\title{
THERMODYNAMICS AND SURFACE STRUCTURE OF COALS
}

\author{
Quarterly Report for the Period
}

April 1, 1990 to July 1, 1990

Patrick C. Wernett, James Maioriello, and John W. Larsen

\author{
Department of Chemistry \\ Lehigh University \\ Bethlehem, Pa. 18025
}

\author{
PREPARED FOR THE UNITED STATES DEPARTMENT OF ENERGY \\ Under Contract DE-AC22-89PC89757
}

\section{DISCLAIMER}

\begin{abstract}
This report was prepared as an account of work sponsored by an agency of the United States Government. Neither the United States Government nor any agency therenf, nor any of their employes, makes any warranty, express or implied, or assumes any legal liability or responsibility for the accuracy, completeness, or usefulness of any infornation, apparatus, product, or process disclosed, or represents that its use would not infringe privately owned rights. Reference herein to any specific commercial product, process, or service by trade name, trademark, anufacturer, or otherwise does not necessarily constitute or imply its endorsernent, recommendation, or favoring by the United States Government or any agency thereof. The views and opinions of authors exprensed herein do not necessarily state or reflect those of the

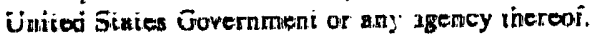

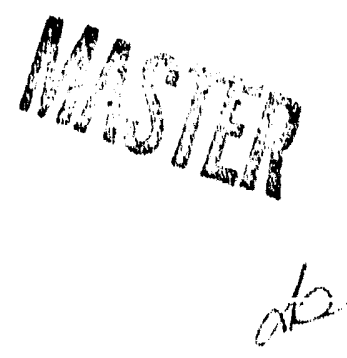

DISTRIQUTION OF THIS DOCUMENT IS UNLIMITED 
SCOPE AND OBJECTIVES OF WORK

\section{Scope:}

The characterization of surfaces and surface chemistry is one of the most active and rapidly growing research areas in all of chemistry. A working knowledge of the surface structure and chemistry of coals is necessary to understand and intelligently optimize processes dominated by surface interactions. In applications such as coal cleaning and coal slurries, the interactions occurring at the coal surface are critical. In all chemical reactions of solid coal, the reagent must first encounter the coal surface. How much of the surface is open to a molecule and the interactions occurring on contact are important, often crucial parameters. Our present scientific understanding of the coal surface and its interactions are rudimentary and inadequate to support the development of new processes and to allow full understanding of the technology which has already been developed, largely on a trial-and-error basis.

\section{Objectives:}

The objectives of this work are to investigate the surface structure and surface interaction chermodynamics of a variety of coals and treated coals in order to develop an understanding of the coal surface and how it changes. The surface structure of coals will be analyzed by:

1) deposition of NMR relaxation agcnts to provide spectra of 
those atoms near the surface which yield direct information about the structure of the surface groups.

2) using ${ }^{129} \mathrm{Xe}$ NMR as a probe to determine pore size distributions and the surface polarity of coals.

3) mapping out the steep dependence of surface area on adsorbate size for a variety of coals.

Thermodynamic studies of coals will studied by:

4) inverse gas chromatography to obtain full desorption isotherms of coals.

5) to use classical calorimetric studies of cual surfaceadsorbate interactions to generate a thermodynamic data base.

\section{Present Work:}

our work this quarter has been the determination of: (1.) the average micropore diameter of three Argonne coal samples by ${ }^{129} \mathrm{Xe}$ NMR spectroscopy; (2) the cyclohexane BET surface areas for the full series of Argonne coals. For a detailed discussion of the relationship between the ${ }^{129} \mathrm{Xe}$ NMR chemical shift and the pore diameter, see DE-AC22-89PC89757-1. The ${ }^{129}$ Xe NMR chemical shift was measured as a function of Xe (g) pressure on Argonne: Wyodak-Anderann (74\% $f$, daf): 
Lewiston-stockton ( $81 \% \mathrm{C}, \mathrm{daf}$ ); and Upper Freeport (87\% C, daf) coals. The coal samples were all desorbed overnight at $10^{-5}$ torr on a Micromeritics Digisorb 2500 stainless steel rig equipped with a ciffusion pump and a Datametrics differential capacitance-type pressure sensor to measure Xe $(g)$ pressures. All NMR spectra were obtained on a Brucker AM $500 \mathrm{MHz}$ NMR spectrometer operating at $138.3 \mathrm{MHz}$. The ${ }^{129} \mathrm{Xe}$ NMR chemical shifts are expressed relative to the free $\mathrm{Xe}(\mathrm{g})$ peak and are always positive.

The ${ }^{129} \mathrm{Xe}$ NMR spectra in descending $\mathrm{Xe}(\mathrm{g})$ concentrations on the Argonne Wyodak-Anderson coal are shown in Figure 1. The peak furthest upfield is due to free $\mathrm{Xe}(\mathrm{g})$ and is assigned a chemical shift value of zero ppm. The downfield resonance, corresponding to $\mathrm{Xe}$ in the Wyodak coal, shows an NMR chemical shift dependence on $\mathrm{Xe}(\mathrm{g})$ pressure and extrapolates to 159 ppm at zero Xe concentration. Applying the method developed by Demarquay and Fraissard ${ }^{1,2}$ to the Wyodak coal, a mean free path of $0.78 \AA$ was calculated, based on the center of the NMR peak. Assuming the coal pores to be spherical, an average pore diameter of $6.0 \AA$ is obtained for this coal. A spherical micropore model for all the coals was assumed based on evidence determined by SANS $^{3}$ and spin probe EPR ${ }^{4}$ methods.

The ${ }^{129} \mathrm{Xe}$ NMR spectra in descending Xe $(g)$ concentrations on the Argonne Lewiston-Stockton and the Argonre Upper Freport coals are presented in Figures 2 and 3 respectively. Based on the same rational and data treatment applied to the Wyodak coal, the Lewiston-stockton coal shows a NMP rhemical shift depcracrac s: 
$\mathrm{Xe}(\mathrm{g})$ pressure and extrapolates to $177 \mathrm{ppm}$ at zero xe concentration. This corresponds to a mean free path of $0.4 \AA$ for $\mathrm{Xe}$ in the coal pore, based on the center of the ${ }^{129} \mathrm{Xe}$ NMR resonance. Assuming spherical pores, an average micropore diameter of $5.2 \AA$ is calculated for this coal. For the upper Freeport coal. (Figure 3), the NMR chemical shift is also dependent on Xe $(g)$ pressure extrapolates to $136 \mathrm{ppm}$ at zero Xe concentration. This corresponds to a mean free path of $1.3 \AA$ for the $\mathrm{Xe}$ atom in the Upper Freeport coal yielding an average pore diameter of $7.0 \AA$.

We have previously observed and reported a steep BET surface area dependence on adsorbate size for an Argonne Illinois No. 6 $\operatorname{coal}^{5}$. During this quarter, the cyclohexane BET surface areas were determined for the entire set of Argonne coals and presented in Table 1. All surface areas were determined on a Micromeritics stainless steel surface area instrument. The 5-point cyclohexane surface areas were measured at an adsorption temperature of $0^{\circ} \mathrm{C}$, allowing 24 hours equilibration time for the first point and 6 hours equilibration time for each subsequent BET adsorption point. 
Figure 1. ${ }^{129} \mathrm{Xe}$ NMR Pressure Dependence Spectra of Argond "Vyodak-Anderson Coal in Shown in Descending $X_{(g)}$ Pressure
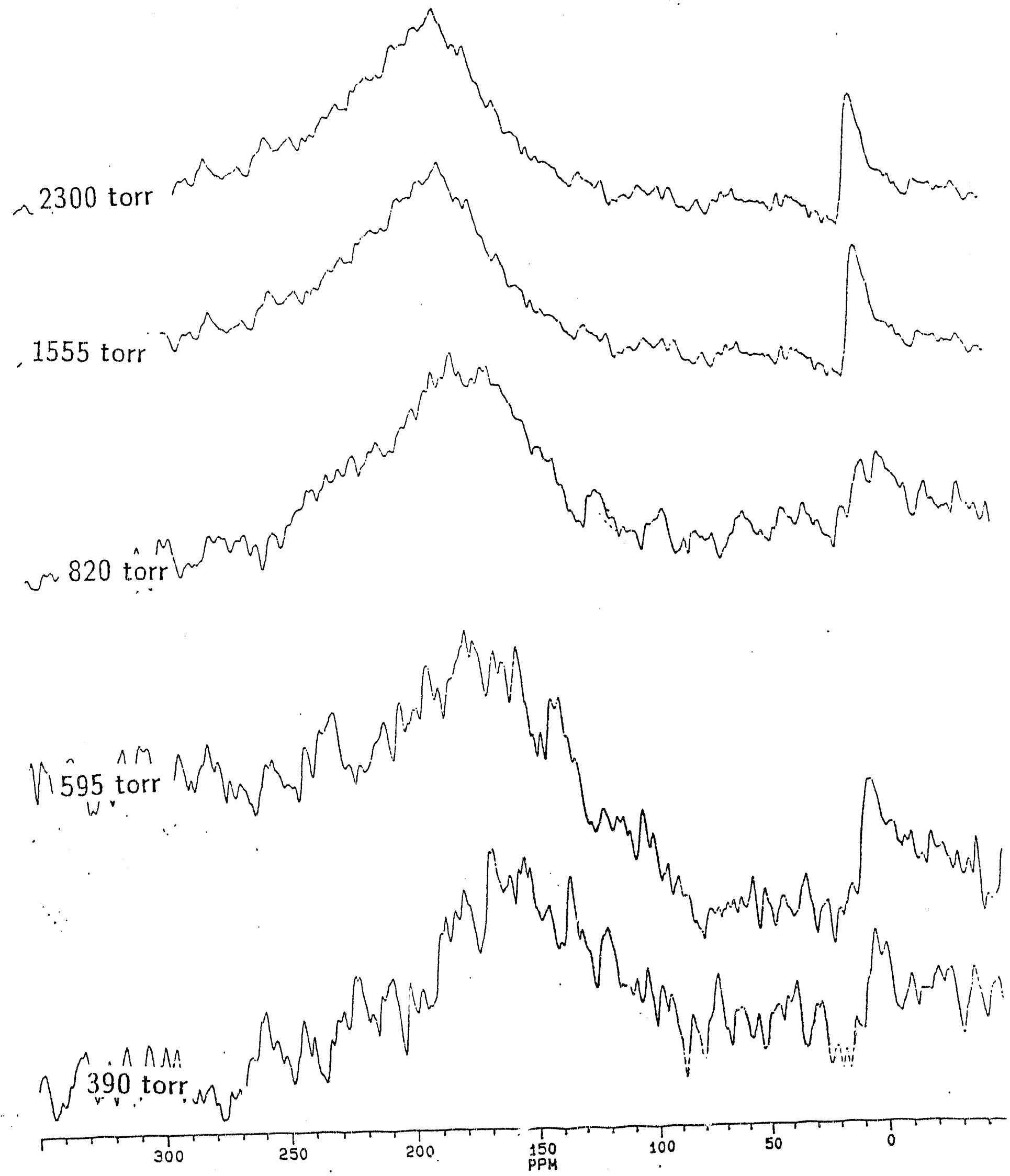
Figure 2. ${ }^{129} \mathrm{Xe}$ NMR Pressure Dependence Spectra of Argonne Lewiston.

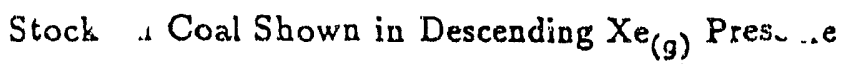

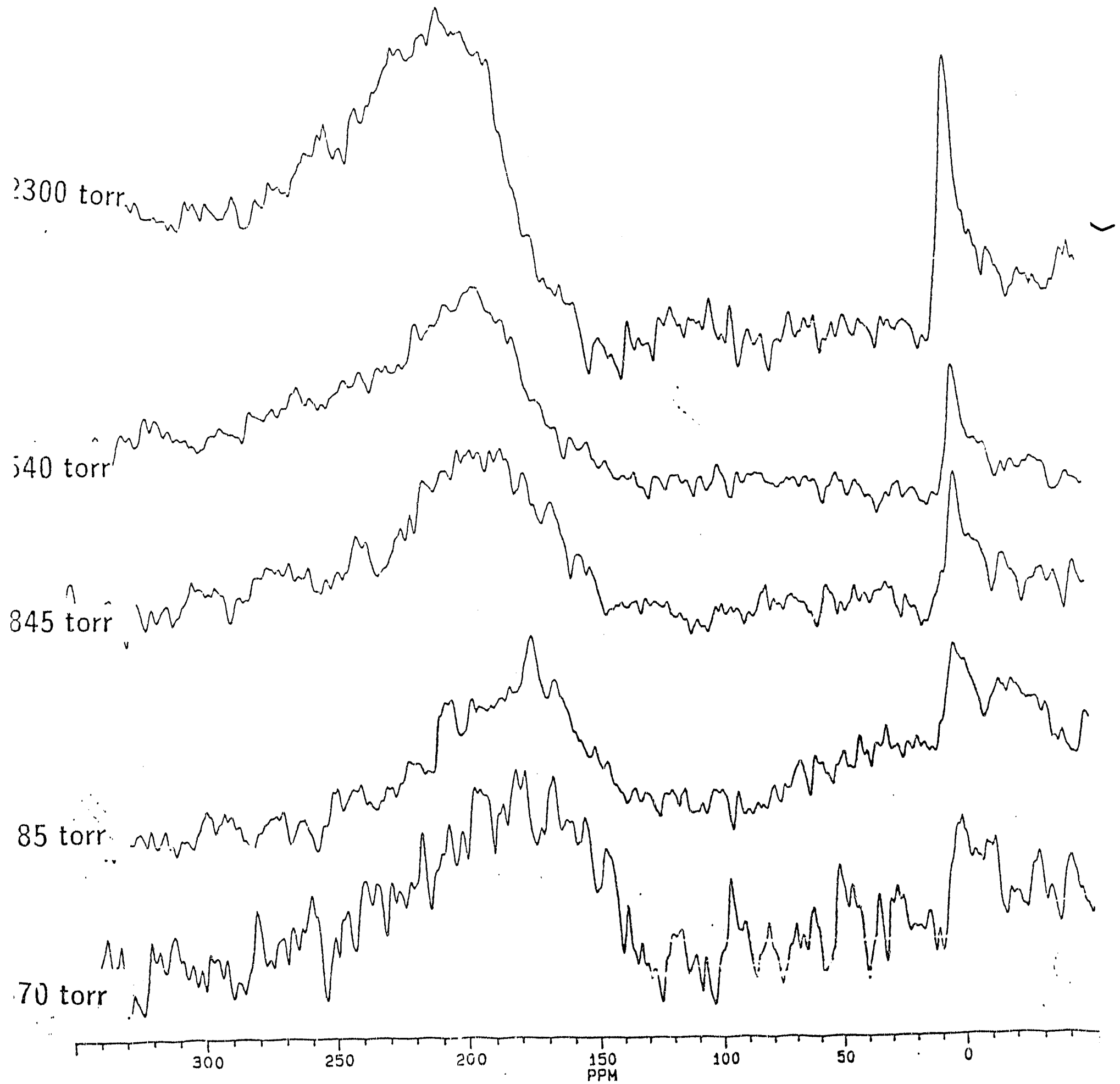


Figure 3. ${ }^{12 y} \mathrm{Xe}$ NMR Pressure Dependence Spectra of Argonne Unper Freeport

Coc lown in Descending $\mathrm{Xe}_{(g)}$ Pressure

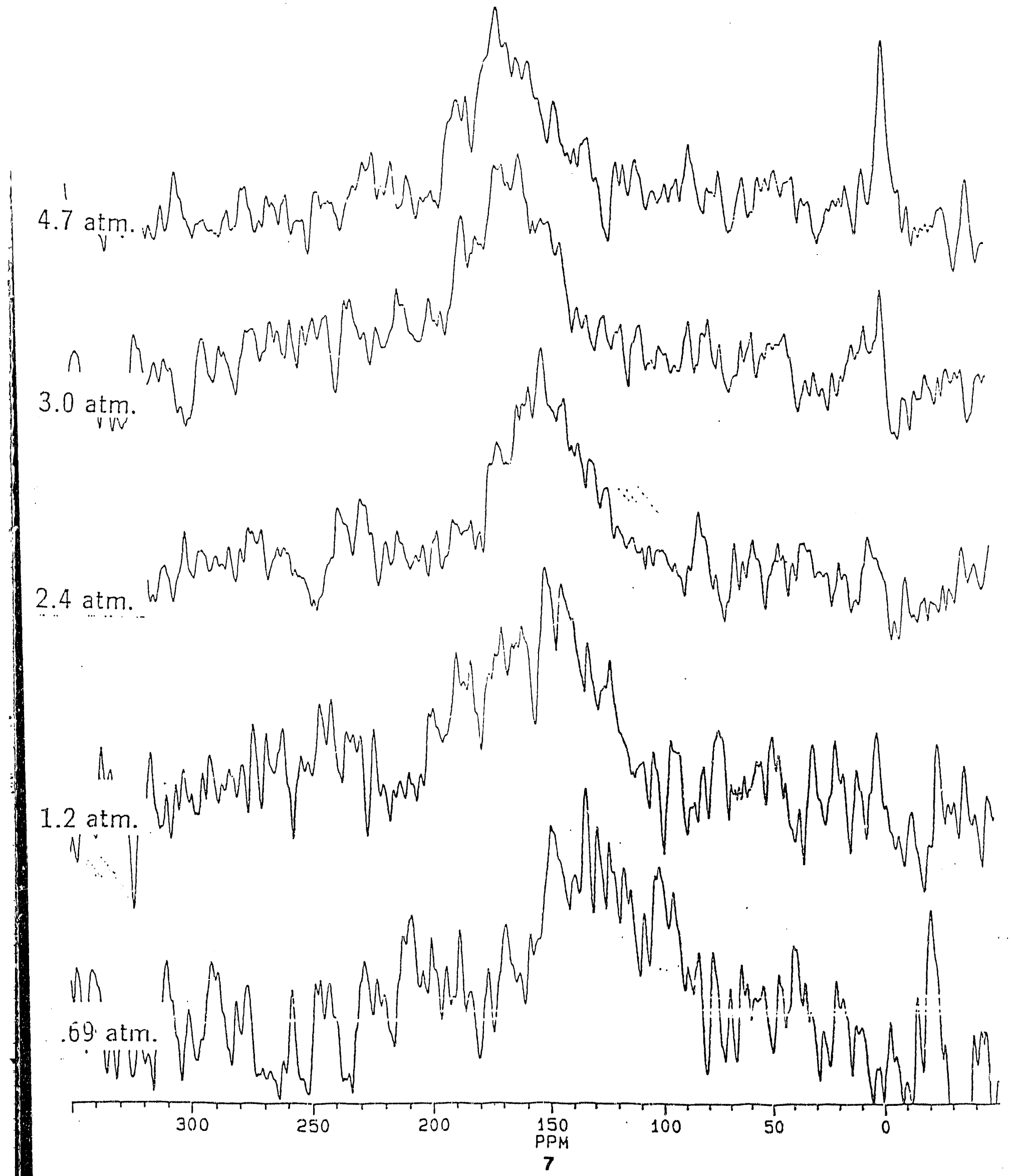


Table 1. BET cyclohexane surface area of Argonne coals

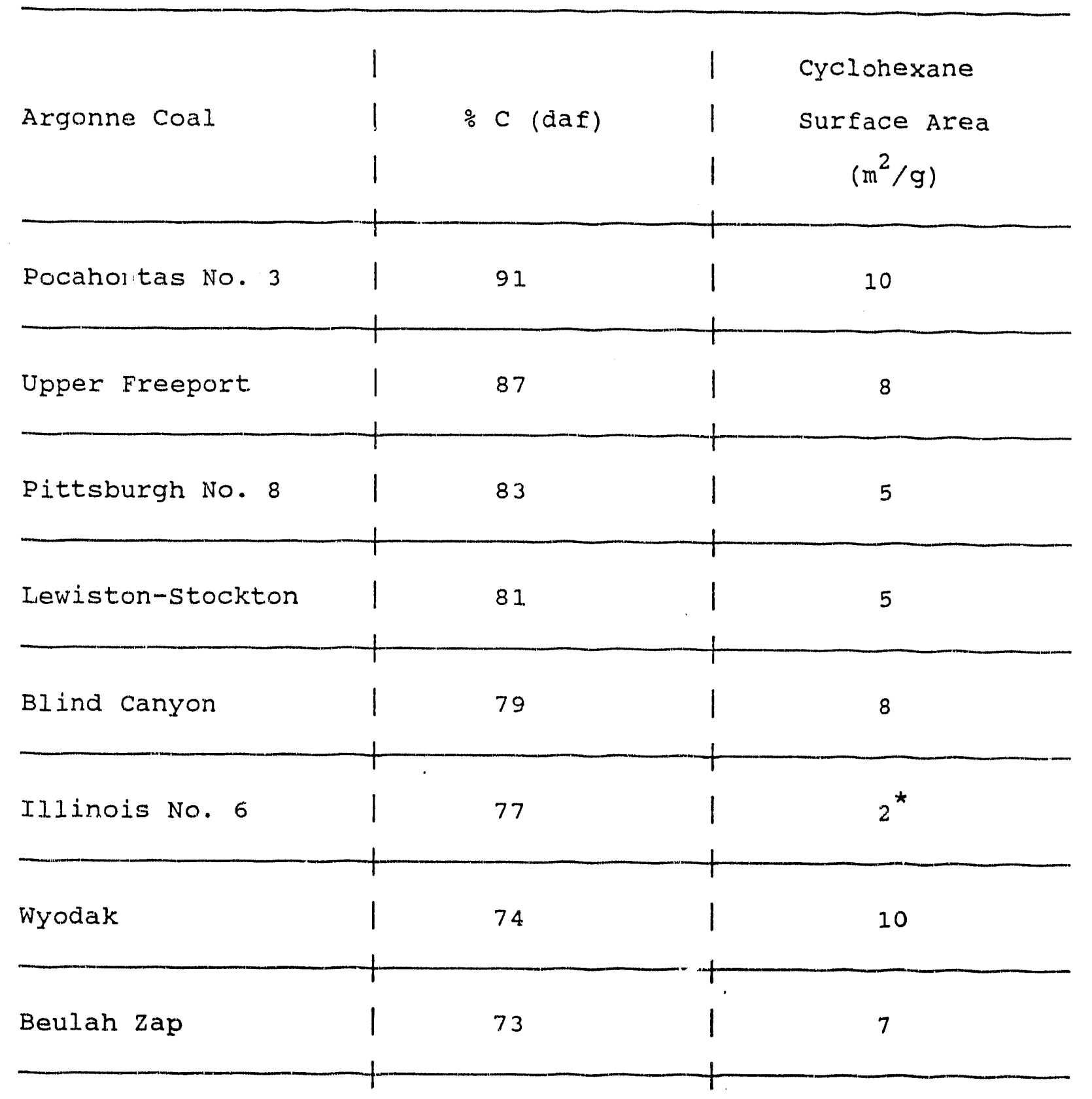

NOTE: *The cyclohexane surface area of the Ilfinois No. 6 coal was obtained at an adsorption temperature of $-20{ }_{C}$ on an all-glass adsorption rig equipped with a Barocel pressure measuring device allowing 6 hrs. equilibration time per BET point. 


\section{REFERENCES}

1. Fraissard, J.; Ito, T. Zeolites 1988, 8, 350-361.

2. Demarquay, J.; Fraissard, J. Chem. Phys. Lett. 1987, 136 (3,4), 314-318.

3. Winans, R. E. ; Thiyagarajan, P. Prepr. Pap. - Am. Chem. Soc., Div. Fuel Chem.1987, $32(4), 227-231$.

4. Goslar, J. ; Kíispert, L. D. Energy Fue/s 1989, $\underline{3}, 589-594$.

5. Larsen, J. W. ; Wernett, P. Energy Fue/s 1988, 2, 719-720. 

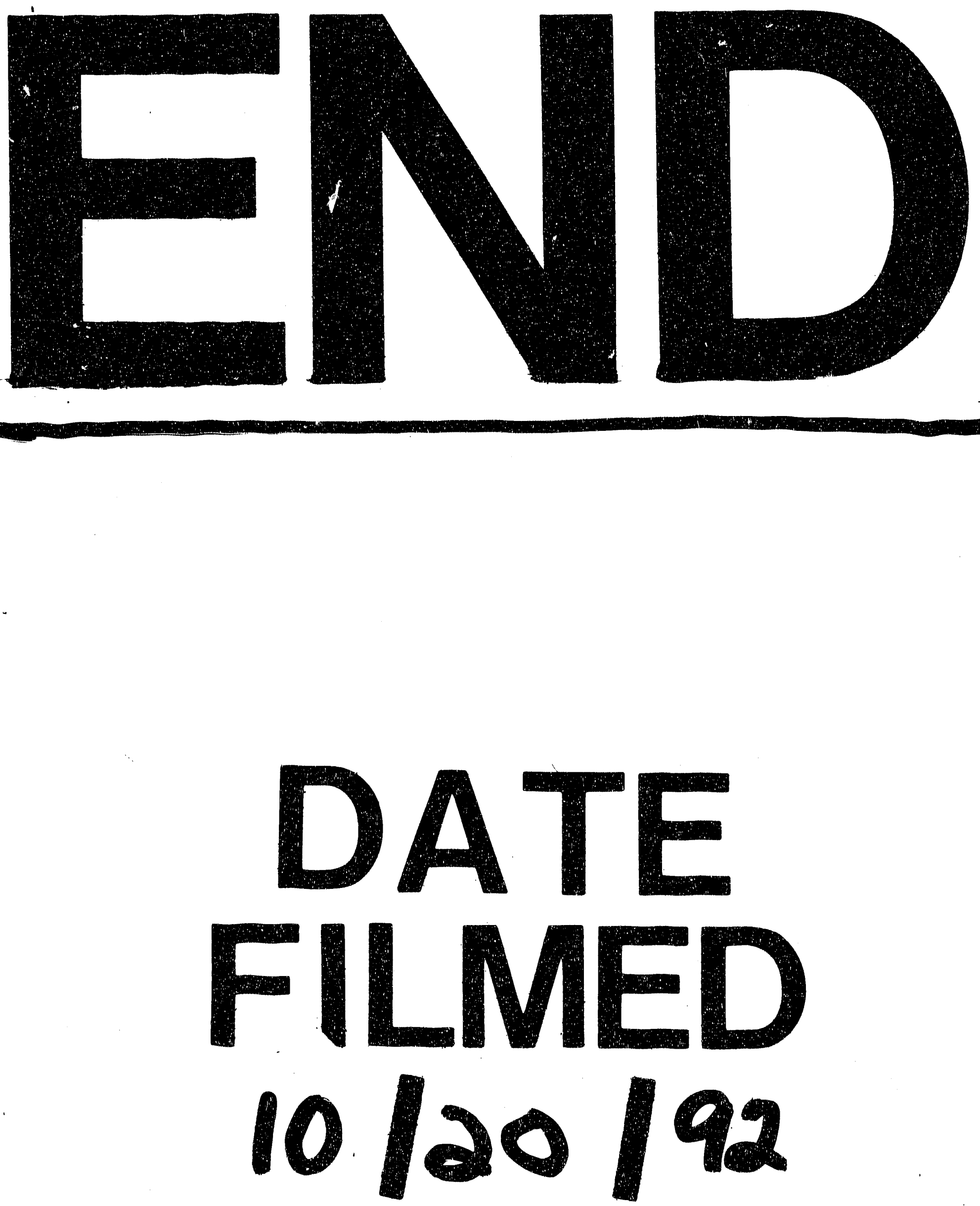
